\title{
A tribute to tributaries: River studies elucidate links between human activity and nutrient export across a broad range of watersheds
}

\author{
This article belongs to Ambio's 50th Anniversary Collection. Theme: Eutrophication
}

\author{
Nina Caraco
}

Published online: 3 February 2021

In my early scientific career in environmental science I was exposed to a great deal of research on $\mathrm{N}$ cycling and transport in forests, wetlands, and coastal waters. Nitrogen was a hot topic because between the 1930s and 1980s, human alteration of the $\mathrm{N}$ cycle had increased dramatically. Nitrogen inputs increased not only to agricultural systems (from fertilizers) but also in precipitation (from fossil fuel combustion), to forested and coastal systems (Vitousek et al. 1997). In addition coastal systems receive nitrogen inputs from groundwater and rivers and the cumulative increase in $\mathrm{N}$ loads increased primary production and associated problems of eutrophication in these systems (Vitousek et al. 1997). Much of the research on nitrogen at this time was carried out at small scales (small watersheds, experimental plots, etc.) where detailed and accurate budgets could be made and experimental manipulations were feasible (Likens et al. 1970). In comparison there were few studies at the regional scale despite the fact that $\mathrm{N}$ pollution is a regional to global-scale problem. Large rivers offer the opportunity to study the impact of increasing $\mathrm{N}$ loads at the regional scale. Further when watershed characteristics are simultaneously collected the controls of $\mathrm{N}$ export can be examined by correlation or simple models. This crosssystem approach was used in the featured Ambio paper (Caraco and Cole 1999a).

The Ambio work was an extension of an earlier crosssystem correlative study that I worked on with colleagues from The Institute of Ecosystem Studies. This study showed that nitrate export from large rivers was well correlated to human population density in the watersheds of those rivers (Peierls et al 1991). In the Ambio paper, we expanded on the population correlation to build a simple model of nitrate export that could do three things: 1 . improve the relationship to human activity (e.g., increase the predictive power); 2 . attribute the $\mathrm{N}$ exports to different human activities that are the sources of $\mathrm{N}$; and 3. calculate the fraction of $\mathrm{N}$ load to the watershed that is exported as nitrate. This model was similar to one that I developed earlier for phosphate export from rivers (Caraco 1995).

The model suggested that $\mathrm{N}$ sources to rivers varied substantially between rivers but on average fertilizer was the most important source (ca. 50\%) followed by precipitation and point sources (both near 25\%). The model also showed that fraction of $\mathrm{N}$ load exported from the watershed as nitrate was explained relatively well by water runoff alone and did not appear to be related strongly to $\mathrm{N}$ load. For example, for the heavily impacted Rhine River, less than $20 \%$ of the $\mathrm{N}$ loaded to the watershed as fertilizer and precipitation is exported to the river as nitrate. Nitrogen saturation is defined by the idea that if $\mathrm{N}$ loading of the watershed goes high enough, the retention of $\mathrm{N}$ in the watershed could decrease substantially (Aber 1992). Our study found little evidence for this saturation but we suggested that future saturation could have devastating effects, increasing dramatically $\mathrm{N}$ export even while $\mathrm{N}$ inputs to watersheds remained constant.

While the Ambio paper presented a highly predictive model, it was deficient in some ways. One obvious problem was that this paper modeled nitrate and not total $\mathrm{N}$ export by rivers. This was done in part as there was a much larger dataset available for nitrate than for total N, but we felt this was justified in that nitrate export appeared to be the most reactive to human impacts examined here. Another problem was that the inputs to the watershed were incomplete. We did not consider $\mathrm{N}$ exchange in crop transport or fixation in forested or agricultural systems. We hypothesized that perhaps the $\mathrm{N}$ originating from atmospheric $\mathrm{N}$ fixation was more likely to be exported as organic $\mathrm{N}$ forms and this would be consistent with organic $\mathrm{N}$ dominating $\mathrm{N}$ export in many pristine systems. Further, while the modeled 
prediction of nitrate export worked for most systems, the predictions were poor for several arid and semi-dry systems where export of nitrate was much lower than predicted. This was despite the fact that our model suggested very high watershed retention in these low water runoff systems $(>95 \%)$. As nitrate export was actually well below predicted point source inputs from sewage, the model suggested that these systems must have high within-river retention either in reservoirs or the river itself. Thus we further examined the high retention in dry systems in a subsequent paper (Caraco and Cole 2000).

To me the most surprising part of this work was not that nitrate export was predicted poorly for some systems but rather the overall good predictions for most systems. We hypothesized that perhaps this result was because the study only examined rivers with relatively large watersheds (10 000 to $1000000 \mathrm{~km}^{2}$ ). At this large scale perhaps all of the systems had areas of high retention such as wetlands, impoundments or intact riparian areas, as well as areas with relatively low retention. If this is the case, then at the smaller scale we would expect that our model of nitrate export would break down. We addressed this possibility in a subsequent study (Caraco et al. 2003). Specifically, we collected data from 249 riverine systems and expanded the range dramatically at the lower watershed size (down to 0.1 $\mathrm{km}^{2}$ ). We then broke these systems into three groups for comparisons: 1 . large $>10000 \mathrm{~km}^{2} ; 2$. mid-size 100 to 10 $000 \mathrm{~km}^{2}$; and 3 . small 0.1 to $100 \mathrm{~km}^{2}$. Surprisingly we found that our model predicted aerial $\mathrm{N}$ export relatively well at all scales even, while the relationship between human population and nitrate export completely broke down at smaller scales. We did find however that in the smallest systems that had a higher fraction of forested cover than the larger systems, our model tended to somewhat over predict nitrate export. The lower export in small largely forested systems could be due to higher retention or gaseous $\mathrm{N}$ loss in forest soils, riparian zones, or streams.

After working up the data for the Ambio paper I presented results at several large meetings, conferences, and workshops. Some of these conferences were open only to invited contributors (e.g., Gordon conferences, Dalhem conferences (Caraco and Cole 1999b)) so an invitation was a positive outcome in that I could fill in some previously rather empty sections of my $\mathrm{cv}$ and annual report. In addition, through participation in a United Nations funded project, I was exposed to modelers who were examining watershed export using fairly detailed spatial data of nutrient inputs to the watersheds (e.g., Seitzinger et al. 2005). On the negative side, in many instances, the response to the presentations was quite antagonistic. One source of this antagonism was, I believe, a general response to the cross-system approach which looks at broad patterns and relate them to only one or a few driving factors. By their very nature, these studies tend to exclude most researchers favorite control variable whether that be forest history, riparian structure, wetland area, and integrity or climatic conditions. Secondly, the paper did not present an ecological solution to controlling increased $\mathrm{N}$ loads such as wetland construction or expanding riparian zones. While these management solutions are important not only potentially decreasing $\mathrm{N}$ export but also reducing soil inputs from agricultural lands, the finding of the Ambio paper of a tight relationship between $\mathrm{N}$ loads and export suggests that decreases in $\mathrm{N}$ load to watersheds and directly to rivers are also critical. Changes in personal and societal behavior that could go far in reducing $\mathrm{N}$ load to rivers include: 1. eating less meat so that fewer crops need to be grown and ammonia input to the atmosphere would be reduced; 2 . using less fossil fuel to reduce the production of atmospheric $\mathrm{N}_{2} \mathrm{O}$; and 3. having fewer offspring to reduce human demand on resources.

Since the 1990s human population, fossil fuel use and N fertilizer use have continued to increase on a global scale despite some declines in Europe. ${ }^{1}$ The increased $\mathrm{N}$ fertilizer use is mostly due to large increases in Asia with China in particular experiencing a very large increase in fertilizer use. In light of these changes it would be interesting to reexamine river export. I have been retired for more than a decade but hopefully a younger scientist will do this sort of analysis. Potentially this analysis might show that relatively simple models predict well not only the shifts in $\mathrm{N}$ export associated with both changes in $\mathrm{N}$ load to watersheds but also climate-driven hydrologic changes that have occurred in the past decades. Alternatively simple models such as the one we presented in the Ambio paper might fail while more mechanistic or spatially explicit models could predict far better current river export.

\section{REFERENCES}

Aber, J.D. 1992. Nitrogen cycling and nitrogen saturation in temperate forest ecosystems. Trends in Ecology and Evolution 7: 220-223.

Caraco, N.F. 1995. Influence of humans on phosphorus transfers to aquatic systems: A regional scale study using large rivers. In Phosphorus in the global environment. Phosphorus cycles and management, ed. H. Tiessen, 235-244. New York: Wiley.

Caraco, N.F., and J.J. Cole. 1999a. Human impact on nitrate export: An analysis using major world rivers. Ambio 28: 167-170.

Caraco, N.F., and J.J. Cole. 1999b. Regional scale export of C, N, P and sediment: What river data tell us about key controlling variables. In Integrating hydrology, ecosystem dynamics, and biogeochemistry in complex landscapes, ed. J.D. Tenhunen and P. Kabat, 239-253. New York: Wiley.

\footnotetext{
$\overline{1 \text { ourworldindata.org. }}$
} 
Caraco, N.F., and J.J. Cole. 2000. Human influence on nitrate export a comparison of mesic and xeric catchments. Marine and Freshwater Research 52: 119-125.

Caraco, N.F., J.J. Cole, G.E. Likens, G.M. Lovett, and K.C. Weathers. 2003. Variation in $\mathrm{NO}_{3}$ export from flowing waters of vastly different sizes: Does one model fit all? Ecosystems 6: 344-352.

Likens, G.E., F.H. Borman, N.M. Johnson, D.W. Fisher, and R.S. Pierce. 1970. Effect of forest cutting and herbicide treatment on nutrient budgets in the Hubbard Brook Watershed-Ecosystem. Ecological Monographs 40: 23-48.

Peierls, B.I., N.F. Caraco, M.I. Pace, and J.J. Cole. 1991. Human influence on river nitrogen. Nature 350: 386-387.

Seitzinger, S.P., J.A. Harrison, E. Dumont, A. Beurson, and A.F. Bouwman. 2005. Sources and delivery of carbon, nitrogen and phosphorus to the coastal zone. An overview of global nutrient export from watersheds (NEWS) models and their applications. Global Biogeochemical Cycles 19: 89. https://doi.org/10.1029/ 2005 GB002606.

Vitousek, P.M., J.D. Aber, R.W. Howarth, G.E. Likens, P.A. Matson, D.W. Schindler, W.H. Schlesinger, and D.O. Tilman. 1997. Human alteration of the global nitrogen cycle: Sources and consequences. Ecological Applications 7: 737-750.

Publisher's Note Springer Nature remains neutral with regard to jurisdictional claims in published maps and institutional affiliations.

\section{Nina Caraco $(\bowtie)$}

Address: PO Box 64, Avon, NC, USA.

e-mail: caraconina@gmail.com 